\title{
In search of potential predictors of erythropoiesis-stimulating agents (ESAs) hyporesponsiveness: a population-based study
}

Ylenia Ingrasciotta ${ }^{1 *+} \mathbb{D}$, Viviana Lacava ${ }^{2+}$, llaria Marcianò ${ }^{3}$, Francesco Giorgianni $^{3}$, Giovanni Tripepi ${ }^{4}$, Graziella D’ Arrigo ${ }^{4}$, Alessandro Chinellato ${ }^{5}$, Daniele Ugo Tari ${ }^{6}$, Domenico Santoro ${ }^{2}$ and Gianluca Trifiròn $1,3,7$

\begin{abstract}
Background: Evidences show that around 20\% of biosimilar or originator erythropoiesis-stimulating agents (ESAs) users are hyporesponsive. Controversial post-marketing data exist on the predictors of ESA hyporesponsiveness. The aim of this study was to identify predictors of ESA hyporesponsiveness in patients with chronic kidney disease (CKD) or cancer in clinical practice.

Methods: During the years 2009-2015, a multi-center, population-based, cohort study was conducted using claims databases of Treviso and Caserta Local Health Units (LHUs). All incident ESA users were characterized at baseline and the differences between the baseline hemoglobin $(\mathrm{Hb})$ value, that is the $\mathrm{Hb}$ registered within 30 days prior to the first ESA dispensing (index date, ID) and each outcome Hb value (registered between 30 and 180 days after ID) were calculated and defined as delta $\mathrm{Hb}(\Delta \mathrm{Hb})$. Incident ESA users were defined as hyporesponsive if, during follow-up, they registered at least one $\Delta \mathrm{Hb}<0 \mathrm{~g} / \mathrm{dL}$. Including all potential predictors of ESA hyporesponsiveness and stratifying by indication for use, univariate and multivariate binary logistic regression models and Receiver Operating Characteristic (ROC) curves were carried out.

Results: 'In general, 1080 incident ESA users (CKD: 57.0\%; cancer: 43.0\%) were identified. In CKD, predictors of ESA hyporesponsiveness were $C$-reactive protein $(\mathrm{OR}=1.2,95 \% \mathrm{Cl}: 1.0-1.5 ; P$-value $=0.060)$ and high levels of baseline $\mathrm{Hb}(\mathrm{OR}=$ $1.7,95 \%$ Cl: 1.2-2.2; $P$-value< 0,001), the latter being also predictor of ESA hyporesponsiveness in cancer (OR = 1.7, 95\% Cl: 1.12.4; $P$-value $=0.007$ ). Both in CKD and in cancer, the type of ESA, biosimilar or originator, was not a predictor of ESA hyporesponsiveness. In CKD, concomitant use of iron preparations $(\mathrm{OR}=0.3,95 \% \mathrm{Cl}: 0.2-0.7$; $P$-value $=0.002)$ and of high dosage of angiotensin-converting enzyme inhibitors/angiotensin II-receptor blockers ( $\mathrm{OR}=0.5,95 \% \mathrm{Cl}$ : 0.3-0.9; $P$-value $=0.022)$ were protective factors against ESA hyporesponsiveness.
\end{abstract}

Conclusions: The study confirmed traditional potential predictors of hyporesponsiveness to ESA. The use of biosimilar or originator ESA was not a predictor of hyporesponsiveness in an outpatient setting from two large Italian areas. A better knowledge of the predictors of ESA response would allow a better anemia management to improve patients' quality of life.

Keywords: Hyporesponsiveness, Erythropoiesis-stimulating agents, Prediction, Claims database

\footnotetext{
* Correspondence: ylenia.ingrasciotta@unime.it

${ }^{+}$Ingrasciotta Ylenia and Lacava Viviana are first authorship shared and contributed equally.

${ }^{1}$ Department of Biomedical and Dental Sciences and Morphofunctional Imaging, University of Messina, Via Consolare Valeria 1, Messina, Italy

Full list of author information is available at the end of the article
}

(c) The Author(s). 2019, corrected publication 2020. Open Access This article is licensed under a Creative Commons Attribution 4.0 International License, which permits use, sharing, adaptation, distribution and reproduction in any medium or format, as long as you give appropriate credit to the original author(s) and the source, provide a link to the Creative Commons licence, and indicate if changes were made. The images or other third party material in this article are included in the article's Creative Commons licence, unless indicated otherwise in a credit line to the material. If material is not included in the article's Creative Commons licence and your intended use is not permitted by statutory regulation or exceeds the permitted use, you will need to obtain permission directly from the copyright holder. To view a copy of this licence, visit http://creativecommons.org/ licenses/by/4.0/. The Creative Commons Public Domain Dedication waiver (http://creativecommons.org/publicdomain/zero/1. 0/) applies to the data made available in this article, unless otherwise stated in a credit line to the data. 


\section{Introduction}

Erythropoiesis-stimulating agents (ESAs) are biological products, analogues of human erythropoietin, produced by cell lines using the recombinant DNA technology. ESAs are approved for the treatment of anaemia related to chronic kidney disease (CKD) or chemotherapy-induced in cancer patients. According to the Italian Medicines Agency, ESAs are indicated when hemoglobin $(\mathrm{Hb})$ levels are lower than $11 \mathrm{~g} / \mathrm{dl}$ in CKD patients and lower than $10 \mathrm{~g} / \mathrm{dl}$ in cancer patients. In Italy, for both indications, haemoglobinemia has to range between 11 and $12 \mathrm{~g} / \mathrm{dl}$ [1], avoiding a rise in $\mathrm{Hb}$ values greater than $2 \mathrm{~g} / \mathrm{dl}$ over a four-week period.

Generally, the term "ESA hyporesponsive" refers to patients who need high doses of ESAs (25-100\% higher doses than what recommended) to increase and/or maintain their $\mathrm{Hb}$ levels within the acceptable range [2]. More specifically, the Kidney Disease Outcomes Quality Initiative (KDOQI) guidelines define patients as ESA hyporesponsive if they do not experience an increase in $\mathrm{Hb}$ levels within the first month of ESA treatment, using an appropriate weight-based dosing (not graded) [3].

ESA hyporesponsiveness could be acute or chronic, but, to date, there is neither consensus nor shared position on the definition of the chronic condition in particular [3]. Based on the definition gave by Sibbel et al., "4 months of continuous ESA hyporesponsiveness [defined considering both Hb concentrations and ESAs doses] can be used to differentiate acute from chronic hyporesponsiveness" [4].

A previously published population-based study, conducted on Italian administrative healthcare databases, evaluated the comparative effectiveness of both biosimilar and originator ESAs in CKD and cancer patients. Results highlighted that, in clinical practice, around 20\% of ESA users were nonresponders, defined as subjects experiencing no variations or a reduction in $\mathrm{Hb}$ levels within the first 3 months of ESA treatment. Furthermore, no differences were observed between different type of ESAs (i.e., biosimilars or originators), in terms of ESA responsiveness [5].

In patients with conservative end-stage renal disease, as well as in dialysis patients, ESA hyporesponsiveness and $\mathrm{Hb}$ level variability may lead to cardiovascular complications, increasing the risk of all-cause mortality, due to the required higher doses of ESA [6-8].

In both CKD and cancer patients, several factors may contribute to ESA hyporesponsiveness, such as iron deficiency, inflammation and malnutrition status, while chronic hyperparathyroidism may affect ESA response in CKD patients, specifically $[9,10]$.

Debate is still on-going regarding the potential effects of renin-angiotensin system inhibitors, such as angiotensinconverting enzyme (ACE) inhibitors or angiotensin II- receptor antagonists (ARBs), on the development of anaemia in patients with renal disease [11].

This naturalistic population-based study was aimed at identifying which factors could be associated to ESA hyporesponsiveness in anaemic patients with CKD or cancer, in the general population of two Italian Local Health Units (LHUs).

\section{Methods \\ Data source}

A population-based, retrospective, cohort study was conducted. As data source, claims databases of Treviso and Caserta LHUs, covering a total population of more than 1.5 million people during the years 2009-2015 (data were available till 2014 in Treviso LHU), were considered. Each prescription of ESA requires a specific therapeutic plan to be filled in by specialists, specifying the exact drug name, number of dispensed packages, dosing regimen and indication for use of the drug. These data can be linked, through anonymized patient unique identifier, to other claims databases including information on hospital discharge diagnoses, healthcare service payment exemptions, drug dispensing, outpatient diagnostic tests, results of laboratory tests (in Caserta LHU, these data are available only for a random sample of around $15 \%$ of the general population), etc. ICD-9-CM diagnosis codes were used to identify hospital discharge diagnoses and indications for use, while Anatomical Therapeutic Chemical (ATC) classification system codes and Italian marketing authorization (AIC) codes, which distinguish reference products from biosimilars and other ESAs still covered by patent, were used to identify drug dispensing. Additional details about data source can be found elsewhere [12].

\section{Study population}

All the residents in Treviso or Caserta LHUs catchment areas in the years 2009-2015 were included in the study, if they had at least 1 year of database history, at least one ESA dispensing during the study period, with no ESAs dispensing within the previous 6 months (i.e. incident ESA users with 6-month washout period), at least one $\mathrm{Hb}$ measurement within 1 month prior to the date of the first ESA dispensing during the study period (i.e. Index Date, ID), defined as baseline $\mathrm{Hb}$ value, and at least another one between the 2nd and the 6th month after ID, defined as outcome $\mathrm{Hb}$ value (Fig. 1).

The included subjects were observed from the month prior to the ID to the first 6 months after the ID.

Patients were excluded in case they received at least one blood transfusion from 1 month prior to the ID to the last observed outcome $\mathrm{Hb}$ value. 


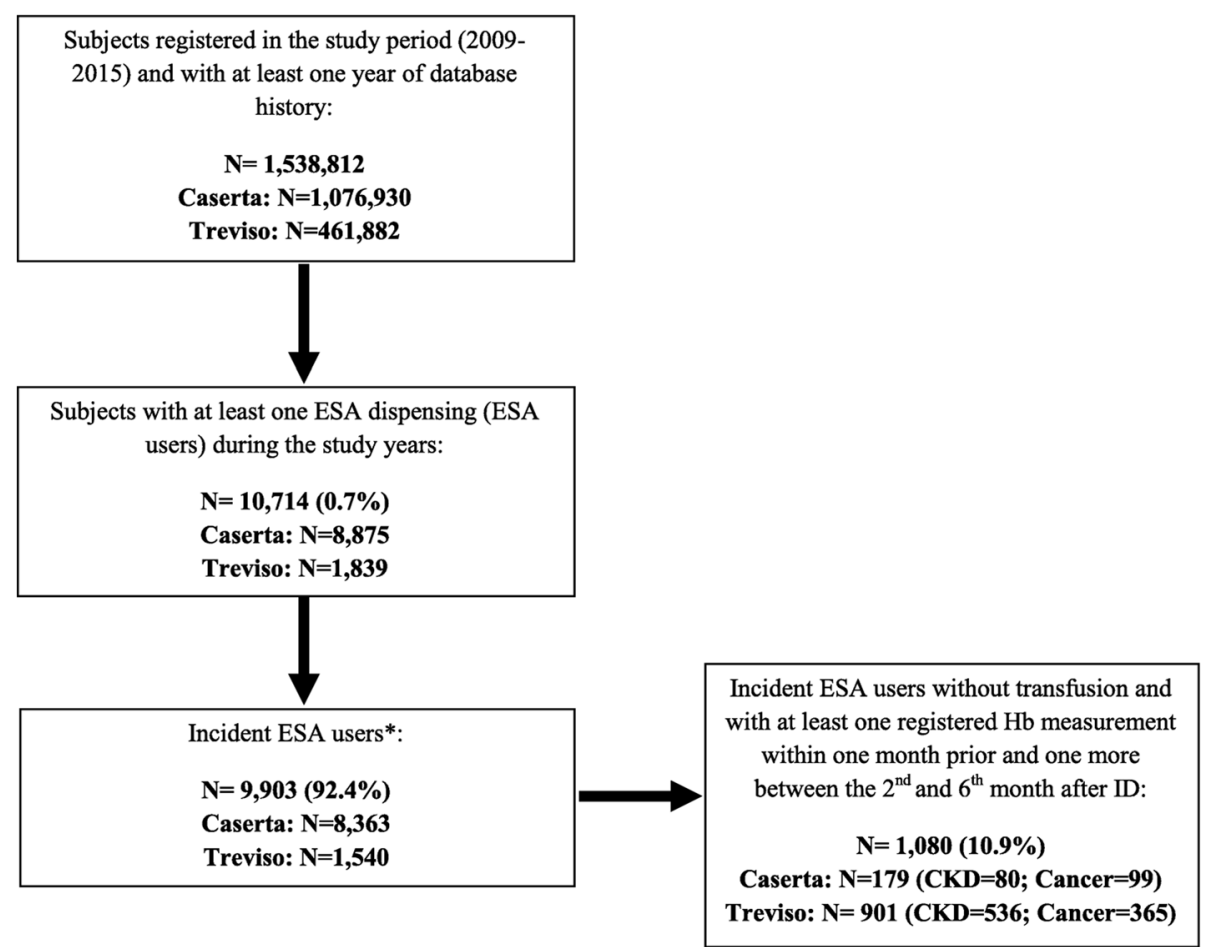

Fig. 1 Flow-chart of study population. * no treatment within 6 months prior to Index Date (ID, i.e. date of ESA treatment start). ESA = erythropoiesis-stimulating agents; $\mathrm{Hb}=$ hemoglobin; $\mathrm{CKD}=$ chronic kidney disease

\section{Study drugs}

All the available ESAs in Italy during the study period were included in the study: epoetin alfa (ATC: B03XA01; Eprex ${ }^{\circ}$, Abseamed $^{\circ}$, Binocrit ${ }^{\circ}$ ), epoetin beta (ATC: B03XA01; Neorecormon ${ }^{\circ}$ ), epoetin zeta (B03XA01; Retacrit ${ }^{\circ}$ ), darbepoetin alfa (ATC: B03XA02; Aranesp $^{\circ}$ ), and methoxypolyethyleneglycol-epoetin beta (ATC: B03XA03; Mircera ${ }^{\circ}$. Binocrit ${ }^{\ominus}$, Abseamed $^{\circ}$ and Retacrit $^{\circ}$ are biosimilars of the reference product $\left(\right.$ Eprex $\left.^{\circ}\right)$, while all other ESAs are ESAs still covered by the patent.

\section{Data analysis}

ESA users were categorized as CKD or cancer patients, according to indication for use recorded in the electronic therapeutic plan. In case of non-availability of electronic therapeutic plans, an algorithm described elsewhere was used to identify indication for use [12].

All incident ESA users were characterized at baseline, in terms of demographics, clinical parameters (e.g. hemoglobinemia and hematic level of creatinine, albumin, ferritin, folate, potassium, sideremia, parathyroid hormone, vitamin $B_{12}$, C-reactive protein (CRP), and transferrin saturation), comorbidities including arrhythmia, ischemic heart diseases, diabetes mellitus, heart failure and hypertension, and concomitant use of iron preparations, folic acid, vita$\min \mathrm{B}_{12}$ and $\mathrm{ACE}$ inhibitors/ARBs.
During follow-up, the distribution of mean $\mathrm{Hb}$ values among incident ESA users was calculated.

The differences between the baseline $\mathrm{Hb}$ and each outcome $\mathrm{Hb}$ value were calculated and defined as delta $\mathrm{Hb}$ $(\Delta \mathrm{Hb})$. Incident ESA users were classified as ESA hyporesponsive if, during follow-up, they registered at least one $\Delta \mathrm{Hb}<0 \mathrm{~g} / \mathrm{dL}$. Only incident ESA users having a baseline $\mathrm{Hb}$ value lower than $11 \mathrm{~g} / \mathrm{dL}$ were included in these analyses.

All analyses were stratified by indication for use.

\section{Sensitivity analysis}

Due to the lack of a shared position on the description of ESA hyporesponsiveness, the definition of ESA hyporesponsiveness was modified in the sensitivity analyses. Incident ESA users with at least two consecutive outcome $\mathrm{Hb}$ values $\geq 11 \mathrm{~g} / \mathrm{dL}$, were classified as ESA responders, irrespective of $\Delta \mathrm{Hb}$. Elsewhere, they were considered as ESA hyporesponsive patients.

\section{Statistical analysis}

Depending on the distribution for quantitative variables, results were presented as mean \pm standard deviation (SD) or median with interquartile range (IQR), and by absolute frequencies and percentages for categorical variables. 
Univariate and multivariate binary logistic regression models were performed to identify predictors of ESA hyporesponsiveness, stratifying by indication for use (CKD and cancer). The dependent variable of the model was the hyporesponsiveness to ESA treatment, that is at least once $\Delta \mathrm{Hb}<0 \mathrm{~g} / \mathrm{dL}$.

As covariates, all the potential predictors of ESA responsiveness identified from the database, including sex, age, baseline $\mathrm{Hb}$ value, ESA dosage at ID, type of ESA dispensed at ID (biosimilar, reference product or other ESAs still covered by patent), LHU, type of hospital discharge diagnosis (categorized into cardiovascular, noncardiovascular or both cardiovascular and noncardiovascular hospitalizations) within 1 year prior to ID, comorbidities (arrhythmia, ischemic heart disease, diabetes mellitus, heart failure, hypertension and dialysis, only for CKD patients), CKD stage or type of tumor (i.e. solid malignant, non-solid malignant, both solid and non-solid malignant, or not classified), concomitant drug use (e.g. iron preparations, vitamin $\mathrm{B}_{12}$, folic acid, high dosage of ACE inhibitor/ARBs) and laboratory values (e. g. hematic levels of creatinine, albumin, ferritin, folate, potassium, sideremia, parathyroid hormone, vitamin B12, C-reactive protein $[\mathrm{CRP}]$, transferrin saturation, acidosis) were included in the model. By restricting potential predictors to all those factors identified from the database, reduce the likelihood of an overstatement.

In the multivariate model, we included all the covariates, which were significantly associated to the outcome at the univariate analysis. For each model, a Receiver Operating Characteristic (ROC) curve was performed to predict the discriminatory power of the variables included in the model.

For each covariate tested as possible predictor of ESA hyporesponsiveness, the corresponding odds ratio (OR) were reported along with 95\% confidence interval (95\% CI).

All statistical analyses were performed using SAS 9.3 (SAS Institute, Cary, NC) and SPSS/PC, Version 21 (SPSS Inc., Chicago, Illinois, USA). The significance level for all statistical tests was set at $p$-value $<0.05$.

\section{Results}

On a total population of $1,538,812$ subjects registered in Treviso and Caserta LHUs, 10,714 (0.7\%) received at least one ESA dispensing during the years 2009-2015; of these, 1080 (10.1\%) incident ESA users were included in the study, based on the above-mentioned inclusion criteria $[C K D=616$ (57.0\%); cancer $=464$ (43.0\%)] (Fig. 1).

As shown in Table 1, ESAs were in general more frequently used by males among CKD patients, and by females among cancer patients. Regarding age distribution, incident ESA users with CKD appeared to be on average older (mean age \pm SD: $72.6 \pm 14.7$ ) than patients with cancer $(66.9 \pm 12.2)$. Although most of ESA users started ESA treatment having baseline $\mathrm{Hb}$ values within the range recommended by the Italian guidelines $(\mathrm{Hb}<10 \mathrm{~g} / \mathrm{dL}$ in cancer and $\mathrm{Hb}<11 \mathrm{~g} / \mathrm{dL}$ in $\mathrm{CKD}), 18.5 \%(N=114)$ of CKD patients and $10.3 \%(N=48)$ of cancer patients started ESA treatment with baseline $\mathrm{Hb}$ values $\geq 11 \mathrm{~g} / \mathrm{dL}$. Around $45 \%$ of incident ESA users received a biosimilar ESA at ID, irrespective of indication of use. In general, CKD patients were more likely to be hospitalized than cancer patients $(66.2 \%$ vs. $56.2 \%)$, especially due to noncardiovascular diseases. As compared to cancer patients, CKD patients were more likely to be affected by chronic comorbidities, such as hypertension (93.2\% vs. $66.8 \%)$ and diabetes mellitus (41.9\% of vs. 25.0\%). Among ESA users with CKD, 410 (66.5\%) were affected by stage IV-V CKD or were on dialysis. Instead, more than one third of cancer patients were affected by solid malignant neoplasms, although for most of cancer patients the type of tumor was not known $(N=208 ; 44.8 \%)$. CKD patients were more likely to be treated with iron preparations (CKD: $18.3 \%$; cancer: $8.4 \%$ ) or anti-hypertensive drugs (ACE inhibitor or ARBs) (CKD: 43.0\%; cancer: 30.8\%) than cancer patients. Considering laboratory parameters, no differences were found among cancer and CKD patients.

The target $\mathrm{Hb}$ value, as recommended by the Italian Medicines Agency, was reached on average between 45 and 60 days after ID and was thereafter stable during follow-up (Fig. 2).

Excluding incident ESA users with baseline $\mathrm{Hb}$ values higher than recommended (i.e., $\geq 11 \mathrm{~g} / \mathrm{dL}$ ), we observed that most of subjects included in the study cohort reached, at least once, the target $\mathrm{Hb}$ values $(11 \leq \mathrm{Hb}$ levels $\leq 12 \mathrm{~g} / \mathrm{dL}$ ), according to recommendations from Italian guidelines, despite 664 (61.5\%) incident ESA users reached $\mathrm{Hb}$ levels $>13.0 \mathrm{~g} / \mathrm{dL}$, at least once during follow-up (Additional file 1).

Table 2 showed that, for each cohort, the proportion of ESA hyporesponsive patients was similar using the two approaches of ESA hyporesponsiveness. According to the given definition of ESA hyporesponsiveness, the multivariate binary logistic regression showed that the type of dispensed ESA (biosimilar or originator) was not a predictor of ESA response in CKD. Moreover, high baseline $\mathrm{Hb}$ values $(\mathrm{OR}=1.7,95 \% \mathrm{CI}: 1.2-2.2 ; P$-value $<$ 0.001) and CRP hematic levels $(\mathrm{OR}=1.2$, 95\% CI: 1.0 1.5 ; $P$-value $=0.060)$ were associated to ESA hyporesponsiveness in CKD (Table 3), while high baseline $\mathrm{Hb}$ values $(\mathrm{OR}=1.7,95 \% \mathrm{CI}: 1.1-2.4 ; P$-value $=0.007)$ and prior ischemic heart disease diagnosis $(\mathrm{OR}=2.7,95 \% \mathrm{CI}$ : 0.97.9; $P$-value $=0.072$ ) were predictors of ESA hyporesponsiveness in cancer patients (Table 4). On the contrary, ESA hyporesponsiveness was decreased by concomitant use of iron preparations $(\mathrm{OR}=0.3,95 \% \mathrm{CI}$ : $0.2-0.7 ; P$ value $=0.002)$ and high dosage of ACE inhibitors/ARBs $(\mathrm{OR}=0.5$, 95\% CI: 0.3-0.9; $P$-value $=0.022)$ in CKD patients and by higher levels of albumin and potassium in 
Table 1 Characterization of incident ESA users at baseline

\begin{tabular}{|c|c|c|}
\hline & $\begin{array}{l}\text { Cancer patients } \\
N=464\end{array}$ & $\begin{array}{l}\text { CKD patients } \\
N=616\end{array}$ \\
\hline \multicolumn{3}{|l|}{ Sex - N (\%) } \\
\hline Males & $217(46.8)$ & $356(57.8)$ \\
\hline Females & $247(53.2)$ & $260(42.2)$ \\
\hline Age - year ${ }^{a}$ & $66.9 \pm 12.2$ & $72.6 \pm 14.7$ \\
\hline \multicolumn{3}{|l|}{ Age category - N (\%) } \\
\hline$<45$ & $22(4.7)$ & $38(6.1)$ \\
\hline $45-64$ & $154(33.2)$ & $126(20.5)$ \\
\hline $65-79$ & $227(48.9)$ & $234(38.0)$ \\
\hline$\geq 80$ & $61(13.2)$ & $218(35.4)$ \\
\hline Baseline $\mathrm{Hb}-\mathrm{g} / \mathrm{dL}^{\mathrm{a}}$ & $9.7 \pm 1.1$ & $10.1 \pm 1.1$ \\
\hline Baseline $\mathrm{Hb} \geq 11 \mathrm{~g} / \mathrm{dL}-\mathrm{N}(\%)$ & $48(10.3)$ & $114(18.5)$ \\
\hline Days of ESA exposure ${ }^{a}$ & $101.8 \pm 40.5$ & $119.4 \pm 41.0$ \\
\hline \multicolumn{3}{|l|}{ ESA dosage during the follow-up ${ }^{a}$} \\
\hline IU & $34,994.1 \pm 9308.1$ & $8564.6 \pm 4835.4$ \\
\hline Mcg & $204.7 \pm 132.1$ & $49.9 \pm 30.0$ \\
\hline \multicolumn{3}{|l|}{ Catchment area $-\mathrm{N}(\%)$} \\
\hline Caserta & $99(21.3)$ & $80(13.0)$ \\
\hline Treviso & $365(78.7)$ & $536(87.0)$ \\
\hline \multicolumn{3}{|l|}{ Type of ESA - N (\%) } \\
\hline Reference product & $129(27.8)$ & $126(20.5)$ \\
\hline Biosimilar & $209(45.0)$ & $284(46.1)$ \\
\hline Other ESAs covered by patent & $126(27.2)$ & $206(33.4)$ \\
\hline \multicolumn{3}{|l|}{ Hospitalizations/PS visits - N(\%) ${ }^{\mathrm{b}}$} \\
\hline No & $203(43.8)$ & $208(33.8)$ \\
\hline Cardiovascular hosp. & $6(1.3)$ & $44(7.1)$ \\
\hline Non cardiovascular hosp. & $244(52.6)$ & $283(45.9)$ \\
\hline Both cardiovascular and non-cardiovascular hosp. & $11(2.4)$ & $81(13.1)$ \\
\hline \multicolumn{3}{|l|}{ Comorbidities - N (\%) ${ }^{c}$} \\
\hline Arrhythmia & $30(6.5)$ & $139(22.6)$ \\
\hline Ischemic heart disease & $23(5.0)$ & $106(17.2)$ \\
\hline Diabetes mellitus & $116(25.0)$ & $258(41.9)$ \\
\hline Heart failure & $28(6.0)$ & $193(31.3)$ \\
\hline Hypertension & $310(66.8)$ & $574(93.2)$ \\
\hline Dialysis & - & $90(14.6)$ \\
\hline \multicolumn{3}{|l|}{ Stage of CKD - N(\%) } \\
\hline $1(\mathrm{GFR} \geq 90)$ & - & $2(0.3)$ \\
\hline $2(90>\mathrm{GFR} \geq 60)$ & - & $11(1.8)$ \\
\hline $3(60>\mathrm{GFR} \geq 30)$ & - & $188(30.5)$ \\
\hline $4(30>G F R \geq 15)$ & - & $230(37.3)$ \\
\hline 5 and dialysis (GFR $<15$ (or dialysis code)) & - & $180(29.2)$ \\
\hline Not classified & & $5(0.8)$ \\
\hline \multicolumn{3}{|l|}{ Type of tumor - N(\%) } \\
\hline Benign & $4(0.9)$ & - \\
\hline
\end{tabular}


Table 1 Characterization of incident ESA users at baseline (Continued)

\begin{tabular}{|c|c|c|}
\hline & $\begin{array}{l}\text { Cancer patients } \\
N=464\end{array}$ & $\begin{array}{l}\text { CKD patients } \\
N=616\end{array}$ \\
\hline Solid malignant & $161(34.7)$ & - \\
\hline Non solid malignant & $72(15.5)$ & - \\
\hline Both solid and non-solid malignant & $19(4.1)$ & - \\
\hline Non classified & $208(44.8)$ & - \\
\hline \multicolumn{3}{|l|}{ Concomitant drugs - N (\%) ${ }^{d}$} \\
\hline Iron preparations & $39(8.4)$ & $113(18.3)$ \\
\hline Vitamin $B_{12}$ & $7(1.5)$ & $12(1.9)$ \\
\hline Folic acid & $37(8.0)$ & $59(9.6)$ \\
\hline ACE Inhibitors/ARBs & $143(30.8)$ & $265(43.0)$ \\
\hline \multicolumn{3}{|l|}{ Laboratory values } \\
\hline Albumin ( $\mathrm{g} / \mathrm{dL}$; normal range: $3.5-5.5)^{\mathrm{a}}$ & $3.6 \pm 0.6$ & $3.7 \pm 0.6$ \\
\hline Creatinine (mg/dL; normal range: $M=0.7-1.2 ; F=0.6-1.2)^{e}$ & $0.9(0.7-1.1)$ & $2.5(1.7-4.0)$ \\
\hline Potassium (mEq/L; normal range: $3.6-5.0)^{\mathrm{a}}$ & $4.4 \pm 0.6$ & $4.7 \pm 0.7$ \\
\hline Transferrin saturation (\%) ${ }^{a}$ & $20.7 \pm 14.3$ & $22.3 \pm 14.1$ \\
\hline Sideremia (mcg/dL; normal range: $\mathrm{M}=75-160 ; \mathrm{F}=60-150)^{\mathrm{e}}$ & $56.0(37.0-83.7)$ & $50.0(33.0-71.0)$ \\
\hline Ferritin (mcg/L; normal range: $M=60-300 ; F=30-150)^{e}$ & $278.4(112.0-583.6)$ & $150.6(59.5-329.3)$ \\
\hline Parathyroid hormone (pg/ml; normal range: $10-60)^{\mathrm{e}}$ & $47.0(27.0-79.0)$ & $160.0(85.0-300.3)$ \\
\hline Vitamin $B_{12}\left(\mathrm{ng} / \mathrm{ml}\right.$; normal range:300-900) ${ }^{a}$ & $491.6 \pm 224.3$ & $506.9 \pm 248.4$ \\
\hline Folate $(\mathrm{ng} / \mathrm{ml} \text {; normal range: } 2.7-17)^{\mathrm{e}}$ & $6.0(3.9-8.8)$ & $5.2(3.5-7.6)$ \\
\hline CRP (mg/dL; normal value: $<0.5)^{\mathrm{e}}$ & $0.9(0.3-4.4)$ & $0.9(0.3-3.1)$ \\
\hline
\end{tabular}

CKD Chronic kidney disease, GFR Glomerular filtration rate, ACE angiotensin converting enzyme, ARBs Angiotensin II receptor antagonists, CRP C-reactive protein, $S D$ Standard deviation, IQR Interquartile range, IU International Unit, Mcg Microgram

${ }^{\mathrm{a}}$ Data are expressed as mean \pm SD

${ }^{\mathrm{b}}$ Evaluated within the year prior to ID

'Evaluated any time prior to ID

${ }^{\mathrm{d} E v a l u a t e d}$ within 3 months prior to ID

eData are expressed as median and IQR

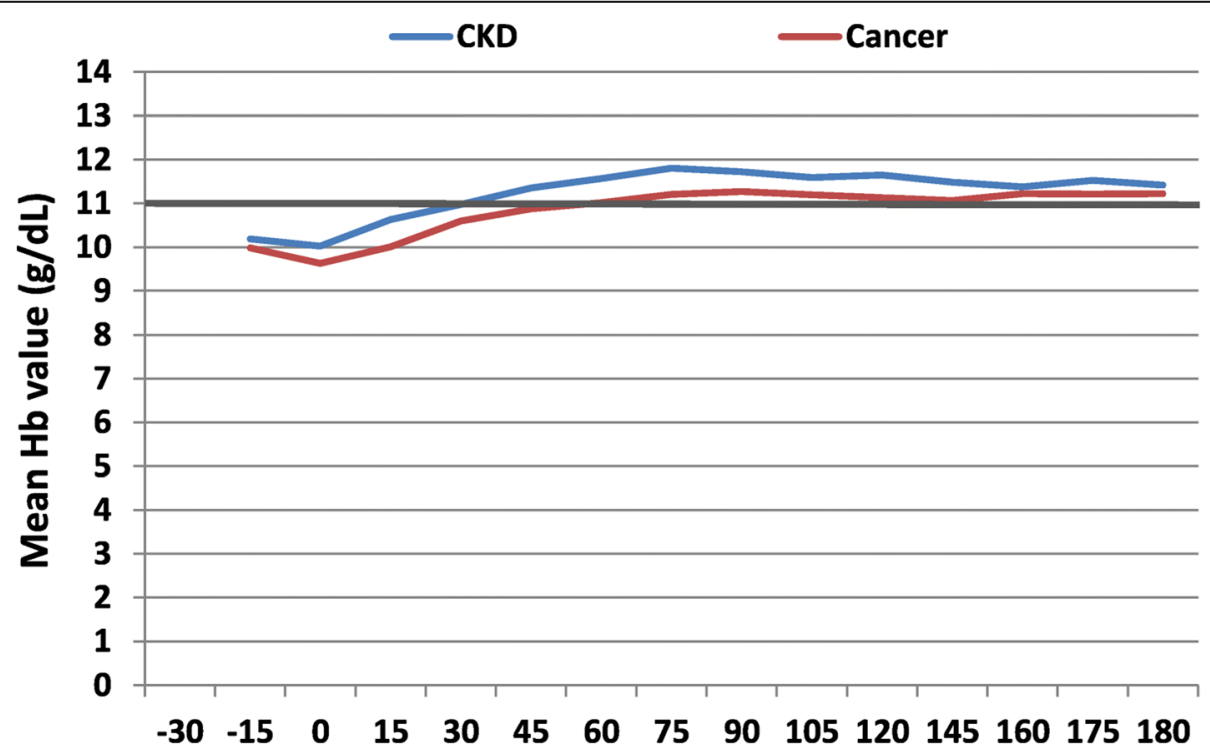

Fig. 2 Mean $\mathrm{Hb}$ variation during the follow-up, stratified by indication for use 
Table 2 Frequency of incident ESA hyporesponders

\begin{tabular}{lll}
\hline & $\begin{array}{l}\text { Cancer } \\
N=416(\%)\end{array}$ & $\begin{array}{l}\text { CKD } \\
N=502(\%)\end{array}$ \\
\hline Non responsiveness & & \\
$\Delta \mathrm{Hb}<0 \mathrm{~g} / \mathrm{dL}^{\mathrm{a}}$ & $146(35.1)$ & $152(30.3)$ \\
$\mathrm{Hb}<11 \mathrm{~g} / \mathrm{dL}^{\mathrm{b}}$ & $135(32.4)$ & $147(29.3)$ \\
\hline
\end{tabular}

Only incident ESA users having a baseline $\mathrm{Hb}$ value lower than $11 \mathrm{~g} / \mathrm{dL}$ were included in these analyses

a Incident ESA users with at least one $\Delta \mathrm{Hb}<0 \mathrm{~g} / \mathrm{dL}$

${ }^{\mathrm{b}}$ Incident ESA users with $\mathrm{Hb}$ values $<11 \mathrm{~g} / \mathrm{dL}$ or with only one $\mathrm{Hb}$ value $\geq 11 \mathrm{~g} /$ $\mathrm{dL}$ registered between the 2 nd and the 6 th month after ID

cancer patients, although not significantly ( $P$-values> 0.005). The discriminatory power of the predictive response of the variables included into the models was good, as confirmed by the ROC curves (Figs. 3-4).

By modifying the ESA hyporesponsiveness definition in the sensitivity analysis, high baseline $\mathrm{Hb}$ value was a positive predictor of responsiveness both in CKD (OR = 0.7, 95\% CI: $0.5-1.0 ; P$-value $=0.053)$ and in cancer patients $(\mathrm{OR}=0.5,95 \% \mathrm{CI}: 0.3-0.8 ; P$-value $=0.003)$; that is, patients with high baseline $\mathrm{Hb}$ values had more chance to reach the target $\mathrm{Hb}$ values rather than patients starting ESA treatment with low baseline $\mathrm{Hb}$ values (Additional files 2, 3, 4, 5). In addition, concomitant use of iron preparations and acidosis condition increased ESA response in CKD patients, with a good predictive power $(\mathrm{AUC}=0.6969 \pm 0.03 ; P$-value $<0.001)$. Moreover, males with $\mathrm{CKD}(\mathrm{OR}=0.5,95 \% \mathrm{CI}$ : $0.3-0.9$; $P$-value: 0.011 ) seemed to be more responsive than females.

\section{Discussion}

Anaemia is a common complication in both cancer and CKD patients and it could contribute to a poor prognosis. ESA therapy represents the main treatment to increase

Table 3 Multivariate binary logistic regression to evaluate non responsiveness to ESAs between the 2 nd and the 6th month after ID in CKD patients

\begin{tabular}{|c|c|c|}
\hline & \multicolumn{2}{|c|}{$\begin{array}{l}\text { Non responsiveness } \\
\Delta \mathrm{Hb}<0 \mathrm{~g} / \mathrm{dL} \text { (at least once) }\end{array}$} \\
\hline & $\mathrm{OR}(95 \% \mathrm{Cl})$ & $P$-value \\
\hline Baseline $\mathrm{Hb}(\mathrm{g} / \mathrm{dL})$ & $1.7(1.2-2.2)$ & $<0.001$ \\
\hline \multicolumn{3}{|l|}{ Comorbidities } \\
\hline Hypertension & $0.8(0.3-1.7)$ & 0.513 \\
\hline \multicolumn{3}{|l|}{ Concomitant drugs } \\
\hline Iron preparations & $0.3(0.2-0.7)$ & 0.002 \\
\hline Folic acid & $0.5(0.2-1.1)$ & 0.100 \\
\hline High dosage ACE inhibitors/ARBs & $0.5(0.3-0.9)$ & 0.022 \\
\hline \multicolumn{3}{|l|}{ Laboratory Values } \\
\hline CRP & $1.2(1.0-1.5)$ & 0.060 \\
\hline
\end{tabular}

Transferrin saturation covariate was excluded because of the high proportion of missing values (>50\%)

CKD ESA users starting the treatment at baseline $\mathrm{Hb} \geq 11 \mathrm{~g} / \mathrm{dL}$ were excluded $A C E$ angiotensin converting enzyme, $C R P$ C-reactive protein
Table 4 Multivariate binary logistic regression to evaluate non responsiveness to ESAs between the 2 nd and the 6th month after ID in cancer patients

\begin{tabular}{|c|c|c|}
\hline & \multicolumn{2}{|c|}{$\begin{array}{l}\text { Non responsiveness } \\
\Delta \mathrm{Hb}<0 \mathrm{~g} / \mathrm{dL} \text { (at least once) }\end{array}$} \\
\hline & OR $(95 \% \mathrm{Cl})$ & $P$-value \\
\hline Baseline Hb (g/dL) & $1.7(1.1-2.4)$ & 0.007 \\
\hline \multicolumn{3}{|l|}{ Comorbidities } \\
\hline Ischemic heart disease & $2.7(0.9-7.9)$ & 0.072 \\
\hline \multicolumn{3}{|l|}{ Laboratory Values } \\
\hline Albumin (g/dL) & $0.7(0.5-1.1)$ & 0.091 \\
\hline Potassium (mEq/L) & $0.7(0.4-1.0)$ & 0.063 \\
\hline $\mathrm{CRP}(\mathrm{mg} / \mathrm{dL})$ & $1.1(0.9-1.3)$ & 0.537 \\
\hline
\end{tabular}

Covariates as ferritin and vitamin $B_{12}$ levels were excluded because of the high proportion of missing values $(>40 \%)$

Cancer ESA users starting the treatment at baseline $\mathrm{Hb} \geq 11 \mathrm{~g} / \mathrm{dL}$ were excluded

$\mathrm{Hb}$ levels in such groups of patients, leading to improvement of quality of life and reducing the risk of cardio- and cerebrovascular complications, as well as the requirement of blood transfusions. However, ESA therapy must be carefully handled due to the increased risk of stroke in older patients having $\mathrm{Hb}$ levels above the target range. Indeed, due to the occurrence of ESA resistance, the need for higher doses of ESA may increase the risk of developing cardiovascular diseases and, ultimately, death [13]. Moreover, Minutolo et al. demonstrated that ESA hyporesponsiveness increased the risk of end stage renal disease by 2.5 -fold in CKD patients [14].

Our data confirmed that the inflammatory condition and the iron intake affect ESA response. Inflammatory cytokines may affect the development of anemia through suppression of bone marrow erythropoiesis, suppression of erythropoietin production, or interfering with the iron status [15]. Several published studies demonstrated that high levels of CRP in hemodialysis patients were associated with ESA hyporesponsiveness, leading to an increased risk of death [16-18]. Although the prevalence of ESA hyporesponsiveness in hemodialysis patients is similar to that found in non-dialysis patients, limited studies on the predictors of ESA hyporesponsiveness have been conducted in the latter population [14].

Regarding the iron intake, our results highlighted that the use of iron preparations was a predictive factor of ESA response, whilst serum iron and ferritin were not independently associated to responsiveness to ESA treatment. Although previous studies on hemodialysis patients demonstrated that an altered iron status (in terms of low transferrin saturation levels and/or low ferritin levels), is a common factor inducing ESA hyporesponsiveness [19], there is no general consensus regarding the role of iron status as a predictor of ESA response. A recent study examined the relationship between iron markers, such as transferrin 


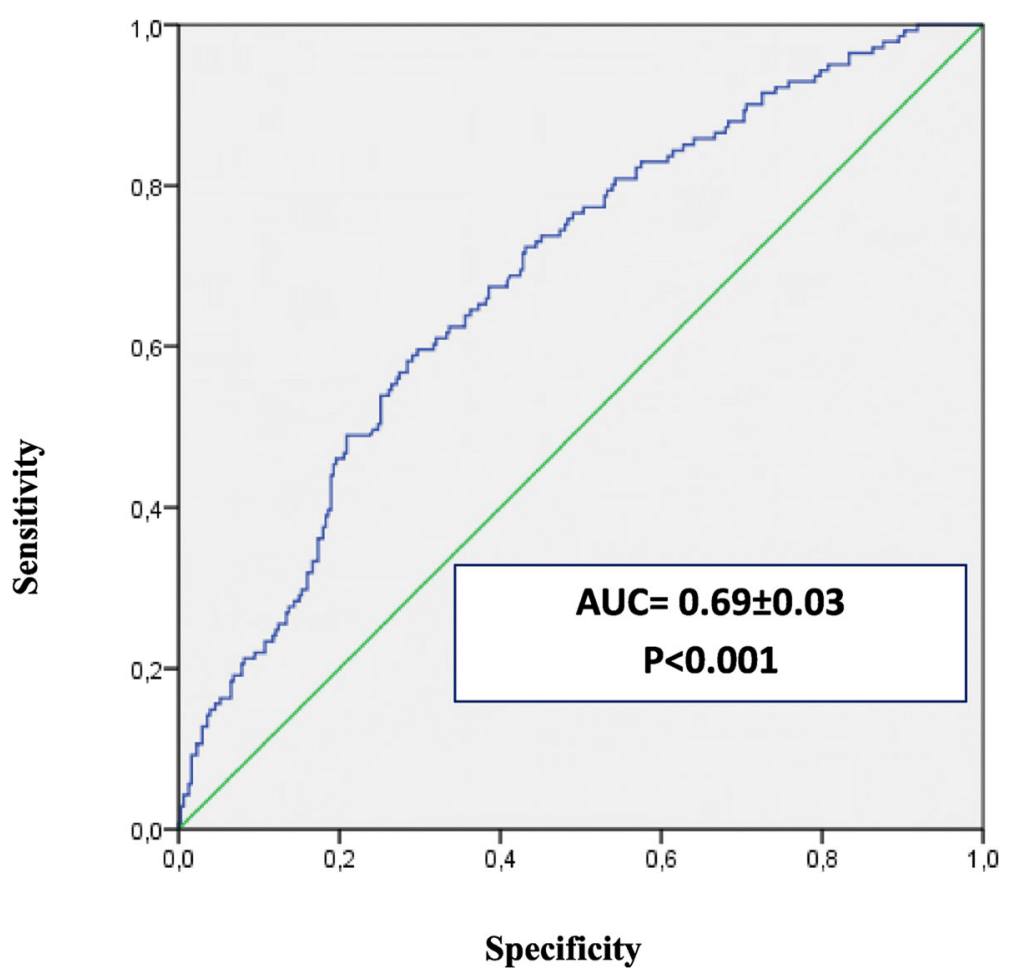

Fig. 3 ROC curve to predict the discriminant power of non-responsiveness in CKD

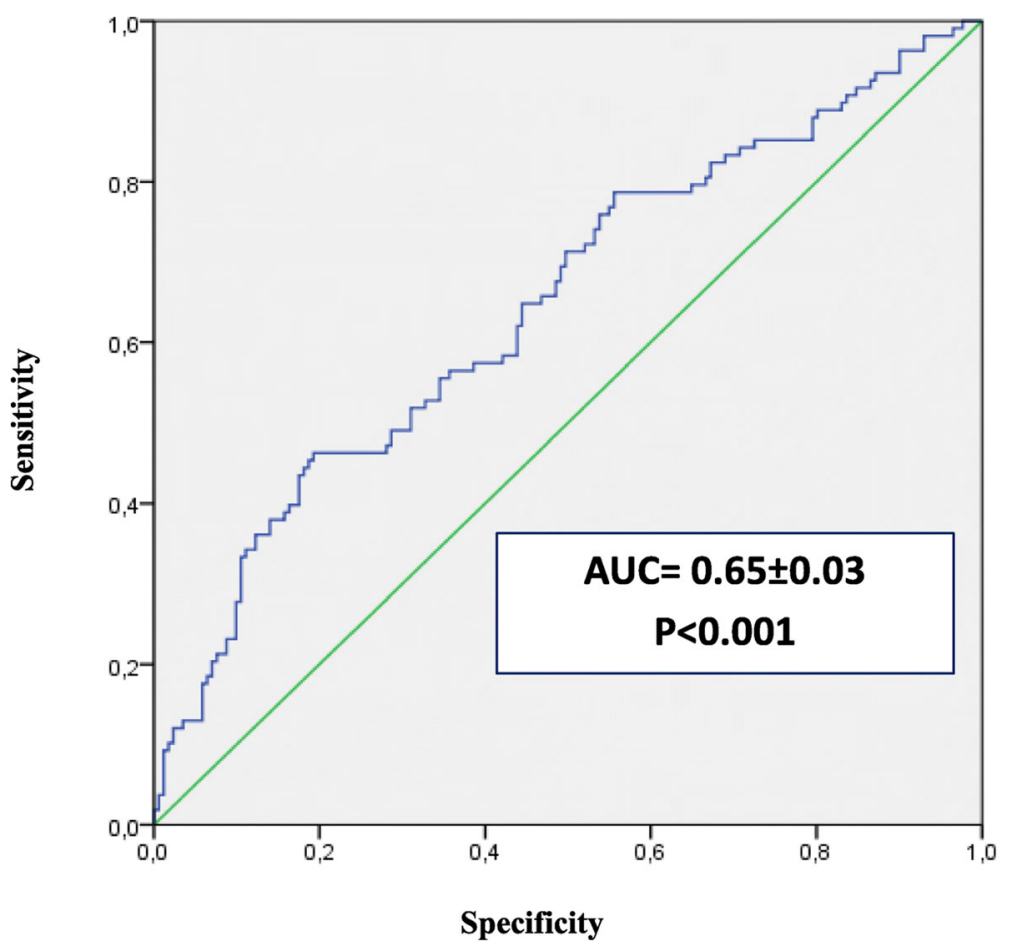

Fig. $4 \mathrm{ROC}$ curve to predict the discriminant power of non-responsiveness in cancer 
saturation and ferritin levels, and ESA responsiveness. Finding from the study highlighted that transferrin saturation, but not ferritin, was statistically associated to ESA hyporesponsiveness [20]. On the hand, in our study, transferrin saturation covariate was excluded from the analysis, due to the high proportion of missing values (> 50\%).

Minutolo et al. studied for the first time the risk of endstage renal disease in CKD patients, who were hyporesponsive to ESA treatment. The study findings demonstrated that ESA hyporesponsiveness correlated to an increased risk of end-stage renal disease and the authors suggested that high ESA doses, together with the persistence of anemia, could lead to hypoxia, tubular atrophy and interstitial fibrosis, thus causing the progression of the renal damage. On the other hand, no correlation between the iron markers, CRP levels, serum parathyroid hormone, body mass index and ESA response was found [14].

The influence of gender on ESA response is still controversial. Female gender was associated with ESA hyporesponsiveness in our study cohort. This result is in line with previous studies $[19,21]$, and may be related to the underlying differences in iron release from reticuloendothelial cells between the two genders [22]. Conversely, other studies demonstrated that males were more likely to be ESA hyporesponsive, in comparison to women [23, 24].

In our study, high doses of ACE inhibitor and/or ARBs were related to ESA responsiveness. This data has been controversially discussed in previous papers. Several studies showing that ACE inhibitors and ARBs are associated to an increase of ESA hyporesponsiveness [23, 25] hypothesized that these anti-hypertensive drugs may interfere with erythropoiesis. It is known that the activation of reninangiotensin system enhances the erythropoietin productions [26], while its inhibition due to ACE inhibitors may exacerbate anaemia [27]. Moreover, it has been demonstrated that ACE inhibitors may cause an increase in serum $\mathrm{N}$-acetyl-seryl-aspartyl-lysyl-proline (Ac-SDKP) levels, which inhibit the recruitment of pluripotent erythroid cells in bone marrow [28]. Other potential mechanisms by which the considered anti-hypertensive drugs may cause anemia are the serum reduction of specific cytokines, such as interleukin-12, and/or of insulin-like growth factor-1, which physiologically stimulate erythropoiesis [11].

Our results also demonstrated that ESA users with metabolic acidosis $\left(\mathrm{pH}<7.38\right.$ and serum $\mathrm{HCO}^{3-}<22 \mathrm{mmol} / \mathrm{l}$ ) had a good ESA response. Due to the lack of evidence explaining such potential association between metabolic acidosis and ESA hyporesponsiveness, further investigations on this potential predictive factor are needed.

Considering cancer patients, we found that higher baseline $\mathrm{Hb}$ values were associated with ESA hyporesponsiveness $(p$-value $=0.007)$, together with the history of ischemic heart disease, although this correlation is close to be significant $(p$-value $=0.072$ ). The role of cardiovascular diseases as predictors of ESA hyporesponsiveness has been previously studied $[18,29]$ in CKD patients and the most liable mechanism is related to an increased production of inflammatory cytokines, such as interleukins 1 and 6, Tumor Necrosis Factor and interferon, which induce apoptosis in erythroid progenitor cells and decrease the iron availability by stimulating hepcidin production [30]. Further analyses are, on the other hand, required to confirm the role of cardiovascular diseases as predictors of ESA hyporesponsiveness in cancer setting.

\section{Strengths and limitations}

This study has several strengths. Firstly, we may explore data on ESA dispensing from two large Italian LHUs over a 7year observation period. Secondly, thanks to the electronic therapeutic plans, information on the exact brand name, number of dispensed packages, and indication for use were available. Moreover, we could explore variations in $\mathrm{Hb}$ values as a result of ESA treatment, using real-world data from more than 1000 ESA users. Most of the previous randomized clinical trials were conducted considering CKD patients only, while our study explored the potential predictors of ESA hyporesponsiveness in both CKD and cancer patients. However, some limitations warrant caution. The high frequency of missing values for some variables considered into the study (namely: transferrin saturation for CKD, as well as ferritin and vitamin B12 for cancer) precluded the possibility to test the independent effect of these risk factors on the study outcome. Thus such an issue remains to be investigated in a specifically designed future cohort study. Furthermore, although we tested into the models a series of laboratory risk factors assessed proximally to the $\mathrm{Hb}$ measurement, the possibility of residual time dependent confounding due to unmeasured confounders cannot be excluded. Some ESA as well as concomitant drugs (i.e. iron preparations) dispensing might not have been fully captured by the LHUs databases, as these drugs may be initially dispensed directly by the public hospitals or purchased by patients as out of pocket, thus not being traced using the study data sources. However, it is unlikely that this limitation affected the study results, as the potential selection bias is expected to be minimal and non-differential between ESAs responders and hyporesponders.

Finally, since the exact body weight of each ESA user was not available and we could not evaluate the exact ESA dosing regimen, we defined ESA hyporesponsiveness as a decrease in $\mathrm{Hb}$ levels and, in the sensitivity analysis, as the failure in achieving $\mathrm{Hb}$ values $\geq 11 \mathrm{~g} / \mathrm{dL}$, as reported by Suttorp et al. in a multi-center, prospective study [7].

\section{Conclusions}

This study tries to identify some potential predictive factors associated with ESA hyporesponsiveness. Covariates 
as serum CRP or high levels of baseline $\mathrm{Hb}$ were confirmed to be associated with poor response to ESA. A better knowledge of the factors associated with ESA response may help avoiding the use of higher ESA doses, and allow a better anaemia management in order to improve the patients' quality of life and reduce morbidity and mortality of both CKD and cancer patients.

\section{Supplementary information}

Supplementary information accompanies this paper at https://doi.org/10. 1186/s12882-019-1554-0.

Additional file 1. Distribution of $\mathrm{Hb}$ values during the follow-up among incident ESA users, stratified by indication for use: a) CKD; b) Cancer.

Additional file 2. Multivariate binary logistic regression to evaluate non responsiveness to ESAs between the 2 nd and the 6 th month after ID in CKD patients.

Additional file 3. ROC curve to predict the discriminant power of nonresponsiveness in CKD.

Additional file 4. Multivariate binary logistic regression to evaluate non responsiveness to ESAs between the 2 nd and the 6th month after ID in cancer patients.

Additional file 5. ROC curve to predict the discriminant power of nonresponsiveness in Cancer.

\section{Abbreviations}

ACE: Angiotensin-converting enzyme inhibitors; AIC code: Italian marketing authorization code; ARBs: Angiotensin II-receptor antagonists; ATC code: Anatomical Therapeutic Chemical code; Cl: Confidence interval; CKD: Chronic kidney disease; CRP: C-reactive protein; ESAs: Erythropoiesisstimulating agents; GFR: Glomerular filtration rate; Hb: Hemoglobin; ICD9-CM code: International Classification of Disease, 9th revision, clinical modification code; ID: Index date; IQR: Interquartile range; IU: International Unit; KDOQI: Kidney Disease Outcomes Quality Initiative; LHUs: Local Health Units; Mcg: Microgram; OR: Odds ratio; ROC curves: Receiver Operating Characteristic curves; SD: Standard deviation

\section{Acknowledgements}

Ylenia Ingrasciotta, Ilaria Marcianò, Francesco Giorgianni, Giovanni Tripepi, Graziella D'Arrigo, Alessandro Chinellato, Daniele Ugo Tari, Domenico Santoro, Gianluca Trifirò are members of the I-BioNetwork. The authorsd thank Caputi Achille Patrizio, lentile Valentina, Bolcato Jenny, Pirolo Roberta Gini Rosa, Roberto Giuseppe, Genazzani Armando, Tari Michele, Pastorello Murizio, Uomo Ilaria, Scondotto Salvatore, Pollina Addario Sebastiano Walter, Cananzi Pasquale, Da Cas Roberto, Traversa Giuseppe, Rossi Mariangela, Davoli Marina, Trotta Francesco, Belleudi Valeria, Addis Antonio who are also members of the I-BioNetwork.

\section{Authors' contributions}

GTrifirò generated the study idea. $Y \mathrm{I}$ and VL wrote the final manuscript. FG, YI, IM, GTripepi, GDA performed the data analysis. DUT and AC extracted the data and authorized their utilization. DS and GTrifirò assisted in interpreting the results under clinical prospective. All authors assisted the results interpretation and manuscript revision. All authors read and approved the final manuscript.

\section{Funding}

This study was conducted in the context of the finalized research project "Assessment of short and long term risk-benefit profile of biologics through health-care database network in Italy" (RF- 2010-2320172), which was funded by the Italian Health Ministry. The financial assistance was used to access and analyze data from different partners.

\section{Availability of data and materials}

The data that support the findings of this study are available from Caserta and Treviso LHUs, but restrictions apply to the availability of these data, which were used under license for the current study, and so are not publicly available. Data are however available from the authors upon reasonable request and with permission of Caserta and Treviso LHU.

\section{Ethics approval and consent to participate}

All procedures performed in this study were in accordance with the Ethical Standards of the Ethics Committee of the Academic Hospital of Messina and of Treviso, according to the current national law [31], and with the 1964 Helsinki declaration and its later amendments or comparable ethical standards. The manuscript does not contain clinical studies, and all patient data were fully anonymized. For this type of study, formal consent is not required.

Consent for publication

Not applicable.

\section{Competing interests}

Gianluca Trifirò declares his participation to advisory boards on biosimilars, organized by Sandoz and Hospira; furthermore, he coordinates a pharmacoepidemiology research team at the University of Messina, which receives research grants for projects that are not related to the topic of the paper. Ylenia Ingrasciotta, Viviana Lacava, Ilaria Marcianò, Francesco Giorgianni, Giovanni Tripepi, Graziella D’Arrigo, Alessandro Chinellato, Daniele Ugo Tari, Domenico Santoro declare that they have no conflicts of interest.

\section{Author details}

${ }^{1}$ Department of Biomedical and Dental Sciences and Morphofunctional Imaging, University of Messina, Via Consolare Valeria 1, Messina, Italy. ${ }^{2}$ Dialysis and Nephrology Unit, University of Messina, Messina, Italy. ${ }^{3}$ Unit of Clinical Pharmacology, A.O.U. Policlinico "G. Martino", Messina, Italy. ${ }^{4}$ CNR-IFC, Center of Clinical Physiology, Clinical Epidemiology of Renal Diseases and Hypertension, Reggio Calabria, Italy. ${ }^{5}$ Pharmaceutical Service, Treviso Local Health Unit, Treviso, Italy. ${ }^{6}$ Caserta Local Health Unit, Caserta, Italy. ${ }^{7}$ Department of Medical Informatics, Erasmus Medical Center, Rotterdam, Netherlands.

Received: 20 September 2018 Accepted: 6 September 2019

Published online: 14 September 2019

\section{References}

1. Determinazione AIFA. Aggiornamento del Piano terapeutico AlFA per prescrizione SSN di Eritropoietine (ex Nota 12). http://www.agenziafarmaco. gov.it/sites/default/files/2010-07-29_determina_aggiornamento_template_ nota_12_g.u._75_del_31-03-2009.pdf. Accessed 12 June 2018.

2. Khankin EV, Mutter WP, Tamez H, Yuan HT, Karumanchi SA, Thadhani R Soluble erythropoietin receptor contributes to erythropoietin resistance in end-stage renal disease. PLoS One. 2012;5:e9246.

3. International Society of Nephrology. KDIGO Clinical Practice Guideline for Anemia in Chronic Kidney Disease. Kidney In Suppl. 2012;2(Issue 4. Chapter 3):299-310.

4. Sibbel SP, Koro CE, Brunelli SM, Cobitz AR. Characterization of chronic and acute ESA hyporesponse: a retrospective cohort study of hemodialysis patients. BMC Nephrol. 2015;16:144

5. Ingrasciotta Y, Giorgianni F, Marcianò I, Bolcato J, Pirolo R, Chinellato A lentile V, Santoro D, Genazzani AA, Alibrandi A, Fontana A, Caputi AP, Trifirò G. Comparative effectiveness of biosimilar, reference product and other erythropoiesis-stimulating agents (ESAs) still covered by patent in chronic kidney disease and cancer patients: an Italian population-based study. PLoS One. 2016;11(5):e0155805.

6. Szczech LA, Barnhart HX, Inrig JK, Reddan DN, Sapp S, Califf RM, Patel UD, Singh AK. Secondary analysis of the CHOIR trial epoetin-alpha dose and achieved haemoglobin outcomes. Kidney Int. 2008;74:791-8.

7. Suttorp MM, Hoekstra T, Rotmans II, Ott I, Mittelman M, Krediet RT, Dekker FW. Erythropoiesis-stimulating agent resistance and mortality in hemodialysis and peritoneal dialysis patients. BMC Nephrol. 2013;25(14):200.

8. Gilbertson DT, Ebben JP, Foley RN, Weinhandl ED, Bradbury BD Hemoglobin level variability: associations with mortality. Clin J Am Soc Nephrol. 2008;3:133-8.

9. Locatelli F, Andrulli S, Memoli B, Maffei C, Del Vecchio L, Aterini S, De Simone W, Mandalari A, Brunori G, Amato M, Cianciaruso B, Zoccali C. 
Nutritional-inflammation status and resistance to erythropoietin therapy in haemodialysis patients. Nephrol Dial Transplant. 2006;21:991-8.

10. KDOQI. National Kidney Foundation. KDOQI Clinical Practice Guidelines and Clinical Practice Recommendations for Anemia in Chronic Kidney Disease. Am J Kidney Dis. 2006;47(5 Suppl 3):S11-145.

11. Macdougall IC. The role of ACE inhibitors and angiotensin II receptor blockers in the response to epoetin. Nephrol Dial Transplant. 1999;14(8): 1836-41.

12. Ingrasciotta Y, Giorgianni F, Bolcato J, Chinellato A, Pirolo R, Tari DU, Troncone C, Fontana A, lentile V, Gini R, Santoro D, Santarpia M, Gennazzani A, Uomo I, Pastorello M, Pollina Addario WS, Scondotto S, Cananzi P, Caputi AP, Trifirò G. How much are biosimilars used in clinical practice? A retrospective Italian population-based study of erythropoiesis-stimulating agents in the years 2009-2013. BioDrugs. 2015;29(4):275-84.

13. Solomon SD, Uno H, Lewis EF, Eckardt KU, Lin J, Burdmann EA, de Zwwuw D, Ivanovich P, Levey AS, Parfrey P, Remuzzi G, Singh AK, Toto R, Huang F, Rossert J, McMurray JJ, Pfeffer MA. Erythropoietic response and outcomes in kidney disease and type 2 diabetes. N Engl J Med. 2010;363:1146-55.

14. Minutolo R, Conte G, Cianciaruso B, Bellizzi V, Camocardi A, De Paola L, De Nicola L. Hyporesponsiveness to erythropoiesis-stimulating agents and renal survival in non-dialysis CKD patients. Nephrol Dial Transplant. 2012;27(7):2880-6.

15. De Francisco ALM, Stenvinkel P, Vaulont S. Inflammation and its impact on anaemia in chronic kidney disease: from haemoglobin variability to hyporesponsiveness. NDT Plus. 2009;2 [Suppl 1:118-26. https://doi.org/10. 1093/ndtplus/sfn176.

16. Kalantar-Zadeh K, McAllister CJ, Lehn RS, Lee GH, Nissenson AR, Kopple JD. Effect of malnutrition-inflammation complex syndrome on EPO hyporesponsiveness in maintenance hemodialysis patients. Am J Kidney Dis. 2003:42:761-73.

17. Kimachi M, Fukuma S, Yamazaki S, Yamamoto Y, Akizawa T, Akiba T, Saito A, Fukuhara S. Minor elevation in C-reactive protein levels predicts incidence of erythropoiesis-stimulating agent hyporesponsiveness among hemodialysis. Patients Nephron. 2015;131(2):123-30.

18. López-Gómez J, Portolés J, Aljama P. Factors that condition the response to erythropoietin in patients on hemodialysis and their relation to mortality. Kidney Int. 2008;74(Suppl 111):S75-81.

19. Kalantar-Zadeh K, Lee GH, Miller JE, Streja E, Jing J, Robertson JA, Kovesdy CP. Predictors of hyporesponsiveness to erythropoiesis stimulating agents in hemodialysis patients. Am J Kidney Dis. 2009;53:823-34.

20. Kuragano T, Kitamura K, Matsumura O, Matsuda A, Hara T, Kiyomoto H, Murata T, Fujimoto S, Hase H, Joki N, Fukatsu A, Inoue T, Itakura Y, Nakanishi T. ESA hyporesponsiveness is associated with adverse events in maintenance hemodialysis (MHD) patients, but not with iron storage. PLoS One. 2016;11(3):e0147328.

21. Mallick S, Rafiroiu A, Kanthety R, lqbal S, Malik R, Rahman M. Factors predicting erythropoietin resistance among maintenance hemodialysis patients. Blood Purif. 2012;33:238-44.

22. Uchida T, Akitsuki T, Kimura H, Tanaka T, Matsuda S, Kariyone S. Relationship among plasma iron, plasma iron turnover, and reticuloendothelial iron release. Blood. 1983;61:799-802.

23. Rossert J, Gassmann-Mayer C, Frei D, McClellan W. Prevalence and predictors of epoetin hyporesponsiveness in chronic kidney disease patients. Nephrol Dial Transplant. 2007;22(3):794-800.

24. Gilbertson DT, Peng Y, Arneson TJ, Dunning S, Collins AJ. Comparison of methodologies to define hemodialysis patients hyporesponsive to epoetin and impact on counts and characteristics. BMC Nephrol. 2013;14:44.

25. Erturk S, Ates K, Duman N, Karatan O, Erbay B, Ertug E. Unresponsiveness to recombinant human erythropoietin in haemodialysis patients: possible implications of angiotensin-converting enzyme inhibitors. Nephrol Dial Transplant. 1996;11:396-7.

26. Vlahakos DV, Balodimos C, Papachristopoulos V, Vassilakos P, Hinari E, Vlachojannis JG. Renin-angiotensin system stimulates erythropoietin secretion in chronic hemodialysis patients. Clin Nephrol. 1995;43(1):53-9.

27. Vlahakos DV, Canzanello VJ, Madaio MP, Madias NE. Enalapril-associated anemia in renal transplant recipients treated for hypertension. Am J Kidney Dis. 1991;17(2):199-205.

28. Azizi M, Rousseau A, Ezan E, Guyene TT, Michelet S, Grognet JM, Lenfant M, Corvol P, Ménard J. Acute angiotensin-converting enzyme inhibition increases the plasma level of the natural stem cell regulator $\mathrm{N}$-acetyl-serylaspartyl-lysyl-proline. J Clin Invest. 1996;97(3):839-44.
29. Guerrero-Riscos MÁ, Montes-Delgado R, Seda-Guzmán M, Praena-Fernàndez $J M$. Erythropoietin resistance and survival in non-dialysis patients with stage 4-5 chronic kidney disease and heart disease. Nefrologia. 2012;32(3):343-52.

30. Van der Putten K, Braam B, Jie KE, Gaillard CA. Mechanisms of disease: erythropoietin resistance in patients with both heart and kidney failure. Nat Clin Pract Nephrol. 2008:4(1):47-57.

31. Ministero della Salute, Agenzia Italiana del Farmaco (AIFA). Circolare AIFA del 3 agosto 2007. Linee guida per la classificazione e conduzione degli studi osservazionali sui farmaci. http://xoomer.virgilio.it/pgiuff/osservazionali. pdf. Accessed 9 Sept 2019.

\section{Publisher's Note}

Springer Nature remains neutral with regard to jurisdictional claims in published maps and institutional affiliations.
Ready to submit your research? Choose BMC and benefit from:

- fast, convenient online submission

- thorough peer review by experienced researchers in your field

- rapid publication on acceptance

- support for research data, including large and complex data types

- gold Open Access which fosters wider collaboration and increased citations

- maximum visibility for your research: over $100 \mathrm{M}$ website views per year

At BMC, research is always in progress.

Learn more biomedcentral.com/submissions 